\title{
Experiencias de familias en relación con su participación en la educa- ción inclusiva de niños y niñas con discapacidad ${ }^{1}$
}

\author{
Family Experiences in Relation to Their Participation in Inclusive \\ Education of Children with Disabilities \\ Claudia Durley Ortiz García* \\ (iD) https://orcid.org/0000-0001-8850-0031
}

Tipo de Artículo: Informes de Investigación y ensayos inéditos

Doi: 10.17533/udea.unipluri.20.2.016

Ortiz García, C. D. (2020). Experiencias de familias en relación con su participación en la educación inclusiva de niños y niñas con discapacidad. Uni-Pluriversidad, 20(2). e20202016. doi: 10.17533/udea.unipluri.20.2.016

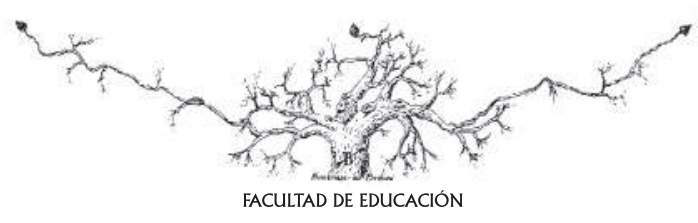

Recibido: 2020-03-25 • Aprobado: 2020-12-14

* Universidad de Antioquia, Colombia.

Email: durley.ortiz@udea.edu.co 


\title{
Resumen
}

En este artículo se presentan los resultados parciales de una investigación hermenéutica realizada con tres representantes de familias de la Institución Educativa Francisco Luis Hernández Betancur, ubicada en la ciudad de Medellín. La investigación indagó el sentido que las familias han otorgado a sus experiencias respecto a la participación en la educación inclusiva del niño o niña con discapacidad. Los hallazgos revelan cómo la experiencia de convivir con una persona con discapacidad puede convertirse en fuente de fortaleza para la familia, asunción de nuevos roles y modificación de las representaciones respecto a la discapacidad; aspectos que inciden en la participación familiar. La composición familiar tiene una implicación directa en las formas de participación, evidenciando una postura patriarcal en la que la mujer es quien debe asumir la responsabilidad, cuidado, crianza y educación del niño o niña con discapacidad y, en consecuencia, ella es quien participa de sus procesos de inclusión mientras el hombre toma un lugar marginal.

Palabras clave: Participación familiar, educación inclusiva, familia, discapacidad

\begin{abstract}
This article presents partial results of a hermeneutical research conducted with three members of families at Francisco Luis Hernández Betancur Educational Institution [I.E. FLHB], in Medellín-Colombia city. The research investigated the meaning they have given their experiences regarding their participation in the inclusive education of children with disability. Findings reveal how the experience of living with a disabled person can become a source of strength for the family, assumption of new roles, and modification of representations regarding disability; aspects that affect family's participation. The family composition has a direct implication with the forms of participation, evidencing a patriarchal posture where the woman must assume responsibility, care, upbringing, and education of children with disabilities, and consequently, she participates in their inclusion process while man takes a marginal place.
\end{abstract}

Keywords: family participation, inclusive education, family, disability. 


\section{INTRODUCCIÓN}

En Colombia, el Decreto 1421 de 2017 reglamenta la atención en educación a las personas con discapacidad, en el marco de la educación inclusiva y explicita en el Artículo 2.3.3.5.2.3.1, que las familias deben ser asesoradas por "las Secretarías de Educación o la entidad que haga sus veces en las entidades territoriales certificadas" sobre "la oferta educativa disponible en el territorio y sus implicaciones frente a los apoyos" (Decreto 1421, 2017, p. 8). Además, debe darse una corresponsabilidad entre familia e institución educativa, mediante la participación de escuelas de familias ${ }^{2}$ en las que se les concientice sobre la educación inclusiva, el derecho a la educación de las personas con discapacidad y sus aprendizajes, entre otros. Es decir, la educación inclusiva no solo tiene en cuenta las características particulares de los estudiantes sino también a la familia como parte de los procesos educativos institucionales.

A manera de contextualización investigativa sobre la participación de familias en la educación inclusiva de niños y niñas con discapacidad, se hizo una amplia revisión de documentos, hallando que la mayoría de las investigaciones son claras en manifestar que la participación familiar puede ser un elemento valioso en el proceso educativo de los estudiantes, en dos de ellas (Valanzuela y Sales, 2016; Castro y García, 2016) se anota que la familia y los estudiantes se ven beneficiados por la participación, además ésta favorece los procesos de inclusión. Marín, Arnaiz y Giménez (2015) por su parte indican que, aunque las familias están informadas respecto a asuntos de la institución que les concierne tales como las políticas y actividades que se desarrollan en ellas, se sigue evidenciando por su parte escases en la toma de decisiones. Con relación a ello Parra, Gomariz, Hernández y García (2017) concluyen que la diferencia contextual entre familia y escuela es causante del alejamiento entre ambas, además que la comunicación entre ellas es poco funcional.

En la investigación desarrollada por Melo (2017) se encontró que las familias asocian la participación solo con asistir a la institución educativa ante llamados de citas y otros, pero los docentes piensan que participar va más allá en tanto implica opinar, aportar y sugerir, en definitiva, hacer parte de la toma de decisiones institucionales que afecten o involucren a sus hijos. En este sentido, la investigación de Beltrán, Martínez y Torrado (2015) invita a pensar la necesidad de examinar estrategias institucionales que permitan articular a la comunidad educativa, en general, en los procesos académicos de los estudiantes e indagar por la pertinencia de éstas como aspecto que pueda aportar al desarrollo integral de los mismos.

En las investigaciones realizadas por Abad (2016); Beltrán et al. (2015) y Ordoñez (2016) se expone que la creación de redes de apoyo por parte de las familias es una estrategia potente que fortalece su participación. Por su parte en la investigación de López (2017) se expresa que la mayoría de los participantes no desean hacer parte de las escuelas de padres, y menos aún, de acompañar al docente en actividades externas; sin embargo, respecto a las actividades del centro y la colaboración en la escuela, la participación es mayor debido a que los pa- 
dres reconocen que son habilidosos respecto al manejo y atención de la discapacidad de sus hijos aportando con ello a la consolidación de la inclusión.

La revisión de investigaciones deja ver la ausencia del reconocimiento de las experiencias de las familias respecto a su participación en la educación de sus hijos. Escuchar la voz de las familias cobra validez en la medida en que solo así es posible comprender, desde sus experiencias personales, cómo entienden y viven su participación en la educación inclusiva de los niños o niñas con discapacidad.

Este artículo muestra los resultados parciales obtenidos a partir de varios encuentros con las familias respecto al sentido que ellas otorgan a sus experiencias participativas a partir de su relación con la institución y otros ámbitos educativos, con las estructuras y dinámicas familiares y desde la experiencia de convivir con un niño/niña con discapacidad.

\section{Metodología}

En consideración con el objeto investigado desde una mirada cualitativa y lo que se pretenda indagar, el estudio se desarrolló desde una perspectiva hermenéutica, en tanto se contempló las experiencias vividas por las familias "como un texto a interpretar desde las visiones de los sujetos y las representaciones sociales y culturales de quienes actúan y participan en la realidad intersubjetivamente construida" (Galeano, 2004, p. 20). Con tal fin se recurrió a la realización de tres talleres con seis familias y a la entrevista semiestructura con tres de ellas, por el potencial que brindan estas técnicas para establecer una comunicación abierta y fluida entre el entrevistado y la investigadora. El cuestionario de la entrevista fue validado, a partir de su experiencia en el tema, por dos expertas en el campo de la educación inclusiva y con amplia trayectoria académica e investigativa. Con base en sus recomendaciones se le hicieron algunos ajustes al instrumento.

Las entrevistas se realizaron con dos madres de 28 y 39 años y una abuela de 56 años, de tres niños con discapacidad (cognitiva - familia $\mathrm{A}$-, auditiva - familia $\mathrm{B}$ - y parálisis cerebral - familia $\mathrm{C}$-, respectivamente). Las tres mujeres se ocupan de las labores del hogar y de atender a los niños y niña, viven es estrato 2 de la ciudad de Medellín, Colombia. En el periodo de desarrollo de la investigación la niña con discapacidad cognitiva cursaba $1^{\circ}$ de primaria, el niño con discapacidad auditiva $2^{\circ}$ y el niño con parálisis cerebral $3^{\circ}$ de básica primaria. Desde la conversación con ellas se buscó la comprensión del sentido que le otorgan las familias, y en particular ellas, acerca de sus experiencias como cuidadoras y educadoras de la niña y los niños, entrando en su mundo simbólico, al significado y realidad de sentido que han construido. Los dos niños y la niña pertenecen a una institución educativa incluyente de carácter oficial del municipio de Medellín que atiende, en su mayoría, familias de estratos socioeconómicos 1, 2 y 3 .

Para realizar el análisis de la información cualitativa recogida a partir de las entrevistas y los talleres, se siguió el procedimiento sugerido por Strauss y Corbin. Se inició con la transcripción de los talleres y las entrevistas, asignación de códigos por colores a los textos in vivo según semejan- 
zas y afinidades. Ordenación de la información resultante en una matriz categorial en la que se registraron las categorías apriorísticas después de hacer la lectura y relectura de los textos, señalando en cada testimonio el tipo de familia, fragmento y número de fragmento $(\mathrm{FaFc} 2)$. En el caso de los talleres el número del taller, fragmento y número de fragmento (T2Fc4). Posterior a ello se dio paso a la

codificación abierta consistente en la selección de fragmentos de discurso y la respectiva asignación de códigos. En este paso se identificaron las categorías principales y se organizaron los contenidos jerárquicamente. Luego se procedió a la codificación axial mediante la creación de un esquema conceptual que agrupaba los códigos [en familias] en aras de efectuar una reducción de los datos y crear categorías de orden superior. Para la codificación selectiva se organizó la información de manera que se fueran eliminando los elementos redundantes, se alimentaron las categorías existentes y se crearon nuevas. Durante este paso se realizó un nuevo proceso de comparación entre las categorías mismas para determinar aquellas que configurarían finalmente la teoría emergente (Strauss y Corbin,2002, pp. 110-26).
En definitiva, para responder al objetivo del estudio, se centró la atención en tres aspectos fundamentales; conceptualización de las familias de la participación, es decir como ellas definen su participación en la educación inclusiva de sus hijos/nieta; sentidos de la experiencia de convivir con un niño/niña con discapacidad, lo que implica las opiniones y sentimientos que esta situación les ha generado y buscando caminos/ encrucijadas de la educación inclusiva, que comprende estrategias implementadas por las familias para la búsqueda y selección de instituciones educativas. Es importante aclarar que algunas de estas categorías contienen sub categoría las cuales surgieron a partir de la implementación del Método de Comparación Constante MCC mencionado en el párrafo anterior. Como ya se dijo, estos aspectos fueron registrados en una Matriz categorial en la cual se asignaron códigos por participante $(\mathrm{Fa}, \mathrm{Fb}, \mathrm{Fc})$, fragmento conversacional $(\mathrm{Fc})$ y número por cada texto in vivo, lo que dio como resultado un código específico para cada testimonio. A continuación, se presentan los resultados parciales de dicha investigación.

\section{Resultados}

\section{Conceptualización de la participación familiar a partir de las propias familias}

En dos de las tres familias acuden a la palabra "acompañamiento" asociándola directamente con la participación, es como si fueran sinónimos. Las tres participantes manifiestan que su participación en la educación de los niños/as se da en todas las actividades que sea necesario acompañarlos, tales como: desplazarse a un lugar diferente a la institución, apoyar en tareas, asistir a una re- unión o un llamado, estar con ellos en clase de natación (caso de las familias A y B). Aun así, algo que genera curiosidad es que aunque tienen claridad de todas estas acciones, en otro momento de la entrevista al preguntarles por su participación en las actividades que realiza la institución, dos de las participantes dicen desconocerlas (familias A y B) más allá de la entrega de notas o las notas escritas por los docentes, las otras acciones parecen invisibles ante los ojos de estas mujeres. Por su parte la familia $\mathrm{C}$ da a entender 
que la falta de compromiso y participación por parte de las familias es motivo para que la institución no realice actividades que las convoque, diferentes a la entrega de notas o reuniones. Frente a esta tendencia aparecen los siguientes testimonios:

Yo nunca he participado como familia con Laura allá, yo no sé si eso si lo hacen y que de pronto el profesor por respeto pues a mi duelo no me haya invitado, porque yo sé que hay un día de la familia, pero a mí no me dijo nada, yo nunca he ido a participar, así como en familia, no. (FaFc81)

Que haga la institución, pues la verdad la clase de lengua de señas es como las actividades así diferentes al colegio. (FbFc55)

[...] pueden hacer muchas actividades, pero es que muchas [familias] como que no se unen $[\ldots]$ o sea siempre sacan algún "pero" [las familias dan excusas para no asistir], el horario, los días, es que no puedo, entonces yo creo que por eso muchas veces tampoco como que sacan esas actividades, digo yo, porque no ven como compromiso (de las familias) (FcFc83)

Esta tendencia llama la atención, debido a que desde lo planteado en el PEI de la IE FLHB y lo vivenciado por la investigadora, con regularidad en la institución se hacen actividades como talleres formativos, capacitaciones a partir de los diferentes programas, asesorías individuales, atención para situaciones específicas en caso de que las madres o acudientes las soliciten o por necesidades institucionales, visitas domiciliarias, entre otras, las cuales tienen como pretensión involucrar a las familias en los procesos educativos de sus hijos.

A partir de conversaciones informales por parte de la investigadora con los docentes y directivos, y lo expresado por algunas familias durante los talleres y entrevistas realizadas en el estudio, fue posible constatar que las técnicas de invitación son citaciones impresas en las que informan las actividades a realizar, además algunos docentes utilizan el medio de WhatsApp para reforzar la información enviada, pero las participantes manifiestan que no son invitadas a las actividades, esta percepción podría estar presente debido a cuestiones comunicativas, es como si la institución más que comunicar informara, es decir, entregan la información sin cerciorarse de que ésta fue comprendida.

Lo anterior invita a pensar en nuevas formas de comunicación o retroalimentación por parte de la institución y las familias que permita constatar que efectivamente la familia recibió y comprendió el mensaje, por ejemplo, haciendo alguna pregunta que incite a la lectura ¿por qué le parece interesante asistir? ello ayudaría a que los mensajes recibidos adquieran un sentido, las familias se vean motivadas a su lectura e incluso en caso de no compresión, poder indagar por los motivos de la citación, comprendiendo que "la comunicación no implique simplemente un intercambio de mensajes sino, sobre todo, una construcción de sentido interactiva" (Duarte, 2006, p. 197). Y para que ello pueda ser posible, se requiere de un reconocimiento por parte de la institución de la importancia de la presencia de la familia, y por parte de las familias, reconocimiento del interés de la institución por su participación, ya que, "tan sólo podremos establecer auténticos puentes de comunicación entre la escuela y la familia si éstas tienen un lugar en ella, si sienten claramente que pertenecen a ese lugar" (Parrellada, 2008, p. 3).

Durante los tres talleres realizados al inicio de esta investigación con 6 familias de la institución, incluidas las tres con quie- 
nes se dio continuidad a este estudio, se evidenció que la participación familiar en la educación de los niños/as con discapacidad está íntimamente relacionada con el acompañamiento y el apoyo que pueda darse al estudiante con discapacidad, esta participación no radica en centrarse exclusivamente en las tareas y visitas a la institución, según las familias, existen otras formas de participar que se interrelacionan con lo académico desde diferentes ambientes, llevarlos al médico, realizar terapias, cumplir con los elementos escolares, inculcar responsabilidad con los horarios y días de asistencia a la institución, conocer los documentos institucionales, comunicarse con el docente por diferentes medios presenciales/virtuales, asistir a las reuniones, aprender otras alternativas comunicativas, enseñar habilidades de la vida diaria, acompañar en las salidas pedagógicas, dedicándoles tiempo y acompañarlos emocionalmente, entre otras.

Las anteriores son formas de participar de las familias que apuntan a favorecer significativamente los procesos educativos de los estudiantes, porque en la medida en que estén bien, podrán aprender, según las voces de las familias la mayoría de estas actividades no son programadas por la institución educativa, se realizan por iniciativa de la familia y en algunas ocasiones en acuerdo con los docentes como lo es el caso de la clase de natación. Algunos de estos aspectos son evidentes en los siguientes testimonios:

Acompañando en la realización de las tareas, uniforme, alimentación, llevarla a la ruta, revisándole cuadernos y recogiéndola, preguntándole cómo le fue en el colegio, revisando la maleta, estableciendo normas a nivel académico, le reviso la cartuchera para enseñarle respeto por los objetos ajenos, le refuerzo temáticas que ven en clase, comunicación constante con la docente. (T1Fc10)
[...] aprendiendo la lengua de señas para poderse comunicar. (T1Fc11)

Hay un acompañamiento médico, este acompañamiento se convierte en participación institucional porque se puede identificar factores asociados a la discapacidad que presenta el estudiante, y el médico brinda una orientación para que la institución realice el trabajo acertadamente. (T1Fc12)

Llevándolos a citas médicas teniendo conocimiento del manual de convivencia, mandándolos a la institución, ayudándole con los trabajos. (T2Fc3)

De acuerdo con estos testimonios, es posible decir que todas aquellas acciones que se llevan a cabo direccionadas al bienestar del niño/a hacen parte de la participación familiar en lo educativo en la medida que se encaminan al fortalecimiento y desarrollo integral de los niños/as, ahora bien, para que ello pueda percibirse de esta manera es necesario que la familia y la institución educativa logren llegar a consensos que les permita interrelacionar los aprendizajes adquiridos en diferentes espacios con aquellos que se dan directamente en la institución educativa. Icho en palabras de Gervilla (2015):

Son infinitas las posibilidades de participación, lo que importa es que cada escuela sea capaz, a partir de los intereses de las familias de las que se nutre, de encontrar los canales adecuados que permitan compartir un proyecto común, contrastar creencias, valores y prácticas educativas (p.151).

En esta medida es preciso afirmar que existen diferentes formas en las que las familias pueden participar, por la relación existente con el niño/a y el conocimiento que tiene de el/ella la información que proporcione al docente, relacionada con "gustos y aversiones, aspectos positivos, cuestiones médicas relevantes" (García, 1994, p. 287). 
Entre otros, cobra validez en tanto permiten enriquecer las prácticas para que sean más efectivas.

\section{Sentidos de la experiencia de convivir con un niño/niña con discapacidad}

Ante la sospecha de la discapacidad en el hijo/a, las expectativas de quienes integran la familia se centran en este acontecimiento, pareciera ser que no hay cabida a pensamientos que desdibujen aquel ideal de persona que se ha construido durante el tiempo de espera. Posterior al nacimiento, alejada de saber que esta nueva persona trae consigo una condición de discapacidad, hay quienes empiezan a notar características particulares que distan de aquello normalmente establecido, palabras como diferente, asociada posiblemente por razones culturales o creencias a algo negativo, como que algo no anda bien y no a una condición propia de todo ser humano "normal", empiezan a circular en los pensamientos de dos de las familias (A y C) y a desatar intranquilidad y curiosidad por saber qué está pasando. Ante la tensión provocada por la esperanza de que todo marcha correctamente y observar que ciertos comportamientos inusuales en los niños deciden acudir a especialistas que puedan ayudar a aclarar lo que sucede. De ello da cuenta el siguiente testimonio.

[...] cuando entró una doctora nueva al plan canguro yo fui la que la empecé pues a preguntar a ella, "ve mi cuñada me pregunta esto, el niño porque no gira, no hace cosas que ya digamos a los 6 meses debería de hacer", entonces ya ella [la doctora] empezó pues a mandarle exámenes, y ahí fue cuando nos dimos cuenta lo que tenía $[. .].(\mathrm{FcFc} 0)$

Pareciera ser que estas familias asocian la diferencia a una condición de falta, quien no posee algunas características socialmente establecidas como realizar determinadas acciones en edades preestablecidas está por fuera de lo normal, esta es una mirada que no admite la diferencia como condición propia de todas las personas, en palabras de Arnaiz (2003) es una "visión que olvida la heterogeneidad inherente al ser humano, que se manifiesta a través de distintos ritmos en el desarrollo evolutivo" (p.149). Es como si la diferencia fuera exclusiva de la discapacidad y no tuviera relación con otras condiciones como las habilidades del niño/a, "la diferencia debería ser considerada respecto a la capacidad, estilos, ritmos, motivaciones y valores culturales" (Arnaiz, 2003, p. 147).

Enterarse de que esa nueva persona trae consigo una condición de discapacidad no es fácil y más aún cuando los especialistas suelen usar tecnicismos poco comprensibles para las familias, caso de la familia $\mathrm{C}$ quien en un primer momento, después de escuchar por parte del especialista que su hijo tenía una parálisis cerebral espástica, se tornó tranquila sin saber lo que sucedía, pero esta actitud cambió notoriamente al comprender que se trataba de una noticia en la que le informaban que su hijo había nacido con discapacidad.

Sentimientos encontrados, seguramente por la ausencia del hijo deseado, como tristeza, dolor, asombro e incluso negación, caso de las familias C y B aparecen como un torbellino para revolcar aquella tranquilidad generada en un primer momento. Tal vez por la incredulidad de aquello que es inevitable surge el deseo de encontrar el culpable, la razón de aquella condición que impide a su hijo ser como los demás, esta aseveración de lo existente frente a la apreciación de lo inexistente puede desencadenar incluso en afecciones físicas y desestabilidad en la persona, así sucedió en la familia B. A continuación, se exponen testimonios de las familias que dan muestra de esta apreciación. 
No porque nos dijeron fue en términos médicos entonces como que no sabíamos como bien qué era entonces no, lo tomamos como tranquilos, ya cuando nos dijeron en sí qué era una parálisis cerebral infantil espástica, sí, a mí sí me dio muy duro. $(\mathrm{FcFc1})[\ldots]$ yo no lo aceptaba, pues yo decía que no que para mí él no tenía eso. [...] él (papá) todavía como que no lo acepta $[. .].(\mathrm{FcFc} 3)$

[...] por parte de la familia tanto mía como la del papá que hay que pobrecito, que eso era culpa mía, o sea empezaron a echar culpas a buscar culpables, el papá del niño no asimiló la noticia porque él pues es, ha sido muy escéptico con todas las cosas $[\ldots]$ pa él fue un golpe demasiado duro se enfermó, como que ya las cosas no eran iguales $[\ldots](\mathrm{FbFc} 2)$

Para ninguna familia es fácil recibir la noticia de que su hija o hijo tiene una discapacidad, situación que se torna aún más compleja cuando la comunicación entre el profesional y la familia no es efectiva. La falta de claridad en la explicación de lo que está sucediendo puede generar en ellas, en un primer momento diversidad de sentimientos, ante ello, Madrigal, A, (2007) indica que "hay padres que expresan quejas por la falta de sensibilidad, la insuficiencia de información o los diagnósticos contradictorios, circunstancias que aumentan los sentimientos de confusión, temor e incertidumbre" (p. 61), que puede llevar a confusiones respecto a lo que realmente está sucediendo y a lo qué deben hacer.

Las reacciones posteriores que tienen las familias ante el reconocimiento de la discapacidad pueden estar estrechamente relacionadas con la concepción de discapacidad que se tenga. Peralta y Arellano (2013) manifiestan que en la actualidad el significado dado a este concepto es más amplio, lo que indica que ya no es atribuido a una patología o una tragedia, sin embargo, "parece exis- tir un consenso casi universal en considerar que las familias perciben la discapacidad de su hijo como un acontecimiento, al menos, estresante" (Peralta y Arellano,2013, p. 1345) lo que podría ser comprensible en la medida que se están enfrentado ante una situación desconocida para ellas.

Los sentimientos generados en primera instancia frente a la noticia pueden variar en tanto las familias logran interiorizar lo que está sucediendo, al menos así se evidenció en este estudio, a medida que se reconoce la condición presente en el niño/niña, los sentimientos iniciales se fueron transformando de diferente manera en cada una de las familias, en la familia B esta noticia fundó en la madre un poder interior que le llevó a asumir esta situación como un reto de superación, no darse por vencida, un impacto positivo, un motivo para salir adelante, forjar un futuro para su hijo en el que no había cabida al fracaso, el deseo por la superación del hijo puede llevar incluso a la superación de los propios temores. En la familia C, el proceso se dio de manera más lenta sin que ello fuera impedimento para alcanzar la aceptación, aun cuando existan cosas que sigan doliendo. Por su parte en la familia A, el sentimiento de terror se transmuta hasta convertir a la niña en el cauce de su fuerza y deseo por seguir adelante. Estas tendencias se ven reflejadas en los siguientes testimonios:

Me iba con ese calor que hacía en pura arena me lo llevaba descalzo, me iba en el caballo cuando ya estaba sudado le quitaban la silla y lo montaban, me tocó montarme a mí, yo le tengo pánico a los caballos y me tocó montarme porque él no se quería montar con nadie más, me tocó subirme yo al caballo y hacerle la terapia, $[. .$.$] ¿qué más no puede$ hacer mi hijo? porque todo lo que usted me diga que no puede hacer, él lo va a hacer [...] (FbFc59) 
[...] hay cosas que a uno le da duro todavía, pero uno como que si las asimila con el tiempo. $(\mathrm{FcFc} 5)$

[...] ya se convirtió en mi tanquecito de oxígeno, pero yo antes no la quería aceptar $[\ldots] \mathrm{FaFc} 7$

Es preciso decir que las familias asimilan en sus vidas la presencia de un hijo con discapacidad de diferente manera, para algunas esta noticia es motivo de tristeza en tanto que para otras es una oportunidad de superación, tener que enfrenar ciertas adversidades y situaciones cotidianas les hace más fuertes, Núñez (2003) indica que en la actualidad, a partir de diferentes estudios, es posible evidenciar que cada día son más las familias que teniendo una persona con discapacidad en casa "no se quiebran o enferman, sino que por el contrario, se sobreponen, enriquecen, maduran, se vuelven más fuertes" (Núñez, 2003, p. 141). Parece ser que la condición de discapacidad después de ser aceptada se transforma en fuente de fortaleza, aunada al deseo de que la persona no se quede estancada debido a su condición, por el contrario, participar en todo aquello que sea necesario es la misión de estas tres familias con la intención de proporcionarles las herramientas necesarias y forjarles un mejor futuro.

Los acontecimientos nuevos e inesperados traen consigo en las personas cambios importantes que pueden verse reflejados en sus sentimientos, pensamientos, ideas, proyectos y acciones, este fenómeno es definido por Larrosa (2006) como experiencia, además este autor agrega que nunca la experiencia puede ser la misma para varias personas aunque el acontecimiento vivido sea similar, es decir, "la experiencia es, para cada cual, la propia, que cada uno hace o padece su propia experiencia, y eso de un modo único, singular, particular, propio"
(Larrosa, 2006, p. 90). Es por ello que para cada familia vivir la discapacidad no ha sido igual, su forma de afrontarla, comprenderla, sentirla, siempre ha estado permeada y atravesada por la propia experiencia, y de ello depende en gran medida la participación en la educación de los niños y de la niña

\section{El modelo patriarcal soslaya la participación de las familias}

Cuando se trata del acompañamiento al niño y la niña con discapacidad, en el caso de las tres familias de este estudio, la figura masculina pareciera no estar presente, desde el inicio de la investigación todas las participantes fueron mujeres, quienes ratificaron la ausencia masculina en la mayoría de aspecto relacionados con sus hijos. En este sentido, se puede decir, que aun cuando se habla de que la familia contemporánea se ha alejado significativamente de la mirada patriarcal, en las tres familias se sigue evidenciado este tipo de prácticas. Respecto a ello Ortega, Torres, Reyes y Garrido (2010) indican que el padre tiende a delegar la responsabilidad a la madre para la educación y la crianza de los hijos (p. 152)

Más allá de que la entrevista hubiese sido respondida por mujeres, en sus relatos se evidencia la ausencia de la figura masculina con relación al cuidado, la educación, la crianza y la salud del niño/a con discapacidad, ya que son las mujeres las encargadas de estos aspectos y por lo tanto ellas son quienes deben hacerse más participes de los procesos, en tanto que el hombre se apersona de las cuestiones económicas e incluso, como se pudo observar en la familia $\mathrm{B}$, se da la ausencia total de la figura masculina en todo lo relacionado con su hijo.

La forma como se asimila la discapacidad en el hombre y en la mujer es diferente, 
en dos de las familias (B y C) fue posible observar que generalmente los sentimientos de negación parecían minimizarse o desaparecer más rápido en las mujeres en tanto que para los hombres aún persiste una actitud negativa frente a la aceptación de la discapacidad, lo que podría conllevar a cambios importantes en los roles familiares e incluso en desintegración de la familia. Además, por el relato de una de las madres se evidencia al hombre como temeroso de no tener capacidades para educar y atender un niño con discapacidad, en tanto la madre sí tiene esa destreza o capacidad natural para hacerlo, generándose él mismo una incapacidad. Estas valoraciones pueden ser constatadas en los siguientes testimonios familiares.

[...] toda la carga fue mía, toda la responsabilidad fue mía [...] él [papá] si como salir a trabajar y el mío todo lo de la casa, las citas médicas, todo, pues ya me tocaba a mi todo. ( $\mathrm{FcFc} 15)$

A mí me tocó asumir los dos roles mamá y papá y la que trabaja y la que pone todo en la casa y la que hace todo el funcionamiento $[\ldots]$ es la que hoy trabaja, pero es la que está en la casa, pero es la que todo. ( $\mathrm{FbFc7}$ )

Con relación a lo anterior no es arriesgado asumir que la participación está definida por los roles culturalmente asignados a la paternidad y la maternidad, pareciera que las madres están destinadas a ser las encargadas de los niños con discapacidad y los hombres tienen un lugar poco representativo en la participación y educación de estos niño/as. Solo en uno de los testimonios el padre, frente a la ausencia de la madre fallecida, es quien toma la determinación de ingresar a su hija a estudiar, pero es la abuela quien finalmente se encarga de todos los asuntos que aquella decisión conlleva. Son las mujeres quienes sacrifican sus acciones, gustos, deseos, sueños, inclusive aspectos relacionados con su salud y bienestar, ante la necesidad y el deber de atender, acompañar y participar en las cuestiones que atañen a los niños/as con discapacidad. Estas apreciaciones son claramente visibles en los siguientes relatos:

[...] dejar de trabajar por dedicarme a cuidar a Sofía, pero no me hace falta, no me importa, estoy bien entre lo que cabe $[\ldots](\mathrm{FaFc} 27)$

$[\ldots]$ entonces tuve que dejar muchas cosas al lado para arrancar con el niño, enfocarme en un apoyo y en una visualización pal niño mejor, entonces tuve que dejar todo de lado para empezar con Johan porque empecé de cero en ese momento. ( $\mathrm{FbFc} 12)$

$[\ldots]$ yo creo que uno va dejando como a un lado la pareja, ese rol de esposa y se enfoca más como en el rol de ser mamá. ( $\mathrm{FcFc} 14)$

$[\ldots]$ el papá yo no cuento [...] si yo tengo algo, él ... usted mira, defiéndase como usted pueda. ( $\mathrm{FcF} 30)$

Ante la presencia de un hijo/a con discapacidad es evidente que los roles maternos y paternos son asumidos de diferente manera. La figura masculina se hace cada vez más ausente en tanto que la femenina está siempre presente, enfrentando de alguna manera las situaciones venideras y siendo partícipe de los procesos del niño/a. Vallejo (2001) reafirma este planteamiento:

Es común identificar que el mayor peso de la responsabilidad a este nivel es delegado y asumido por las madres, las mujeres. Son ellas, las que asumen - en ocasiones de manera estoica - el compromiso de "sacar adelante a sus hijos", haciendo frente a cualquier adversidad, asumiendo cualquier costo, hasta el descuido y la renuncia hacia sí misma (p.5).

Pareciera ser que las familias que tiene hijos/as con discapacidad están destinadas a permanecer bajo el dominio de una mirada 
patriarcal, en la medida en que las mujeres siguen ancladas, en estos tres casos en particular, al sometimiento a partir de la ausencia de la imagen paterna obligándolas a quedarse en casa y hacerse responsables y partícipes de todo lo relacionado con el niño/a con discapacidad, bajo un apelativo de "mujer y madre amorosa y cuidadora" (Palacio, 2010, p. 17).

En el caso de estas tres mujeres se sigue evidenciado la delegación de funciones propias de la familias tradicionales cuyo abanico de posibilidades se reduce al sometimiento del hogar, la crianza, el cuidado y la educación de los hijos, en ninguno de estos tres casos la mujer pudo decidir el camino a tomar, se han visto enfrentadas a las renuncias personales, sueños, metas y anhelos ante la falta de una figura masculina que les apoye y acompañe en los ámbitos en los que los niños/as lo requieran, destacando el educativo. Además, podría decirse que la discapacidad de un hijo incide en que el hombre tome decisiones extremas incluso de abandono y de alejarse hasta el punto de que es la mujer quien debe responsabilizarse de ellos. Respecto a esto Ortega, et al., (2010) exponen:

El padre puede abandonar el hogar y no compartir la situación actual relacionada con los hijos, además de delegar toda la responsabilidad a la madre sobre la crianza y la elección del tratamiento o búsqueda de escuela especial donde pueda ingresar el niño para recibir ayuda profesional y garantizar el rendimiento escolar y el éxito en su desarrollo personal (p. 152).

En esta medida, la colaboración de otras personas se hace necesaria ante el agotamiento que pueden alcanzar las mujeres que están a cargo de los niño/as con discapacidad, la presencia puede ser de manera virtual o física, lo importante es tener a al- guien con quien contar. En uno de los relatos (familia A), un miembro de la familia está presente como recurso que apoya y genera tranquilidad, incluso la niña ha sido impulso de unión entre ellas. En la familia C la presencia de la familia que vive en otro país se hace evidente por medio del WhatsApp $\mathrm{y}$, aunque el apoyo es a distancia, este ayuda a minimizar un poco el sentimiento de soledad, es lo que Palacio (2009) denomina "familia transnacional [...] incorporar la tecnología y la comunicación virtual como los cimientos de un escenario diferente para con-vivencia familiar" (p.58).

Los hermanos de niños/as con discapacidad se convierten en un eje fundamental en tanto brindan tiempo, acompañamiento y modelado de acciones impulsando con ello el aprendizaje del niño/a, de esto dan cuenta las familias C y B quienes ante la ausencia de un familiar adulto que acompañe, cuentan con el otro hijo/a de manera incondicional. Ante ello las familias pronuncian los siguientes testimonios:

[...] me ayuda mucho con ella, para ella somos como las dos mamás, porque Marta [hermana de la abuela] para ella es total y yo cuando está con ella yo soy tranquila porque yo sé que ella la cuida hasta mejor que yo, de todas maneras, ella es profesora $[\ldots](\mathrm{FaFc} 48)$

[...] la niña incluso entró al grupo del INDER pues haciendo el acompañamiento al hermano que siendo ellos contemporáneos, porque no se llevan sino un año de diferencia, quién le copea mucho a ella [...] $(\mathrm{FbFc17})$

[...] los médicos... neurólogo y cuando yo la llevaba pues así pequeña me decían si no fuera por ella [la hermana menor] él no estaría como ésta, la mejor terapeuta que él ha tenido ha sido 
ella. [...] desde el momento en que empezó a gatear él la empezó a imitar a ella en todo $[\ldots](\mathrm{FcFc} 92)$

Tener a cargo un niño/a con discapacidad puede generar cansancio y agotamiento físico y emocional, contar con el apoyo de otras personas puede ayudar a alivianar un poco la carga, sobre esto Núñez, Páez y Pérez (2017) opinan que la familia extensa cobra gran valor en la medida que puede aconsejar ante la presencia de situaciones que el cuidador por sentirse cargado o tensionado no puede o no sabe cómo atender. En este sentido y en relación con lo observado en el caso de la familia A este tipo de acompañamiento también pude ser fuente de tranquilidad ya que, genera espacios de intimidad para que la abuela pueda reorganizar sus ideas, tomar un aire y retomar su labor con serenidad.

\section{Buscando caminos: encrucijadas de la educación inclusiva}

Acompañar a los niños y las niñas en sus compromisos académicos, esperando que ellos puedan aprender algo más es la meta de estas tres mujeres, quienes coinciden en señalar que ayudar en ello requiere tiempo y paciencia, dos de ellas (familia A y C) refieren que no es fácil, quizás por la falta de conocimientos y el tiempo que hay que invertir en explicaciones, la familia B indica que para ella es mucho más sencillo apoyar en lo académico pues siente tener el bagaje y las capacidades para hacerlo, pareciera ser que la participación de estas tres mujeres se convierte en parte vital del proceso académico del niño/a sin importar si tienen o no los conocimientos técnicos necesarios; lo que sí es claro, es que en casa ayudarlos a hacer tareas, idear estrategias, cargarse de paciencia y volver a repetir cuantas veces sea necesa- rio, se convierten en acciones participativas cotidianas encaminadas al fortalecimiento académico de los niños/as. Así, lo señalan las familias:

Le hago primero la plana a ella en una parte, en una hoja diferente como una muestra y ella la va pasando, después hago que ella lo haga sola, pero le da dificultad $[\ldots](\mathrm{FaFc} 41)$

Unos tronquitos, no sé cómo se llaman, unos palitos de madera, [...] otro que es como con unos tubitos y con unos frijolitos, entonces meterlos por unos tubitos para contar, o le digo yo, entonces con los palitos, traiga otro cuaderno y hágalo con los palitos y cuente acá, sí, como implemento como varias cosas entonces por lo mismo mucha más paciencia, más dedicación, sentarme con él y tenerle que explicar más [...] $(\mathrm{FcFc} 22)$

[...] pero ya en la actividad o sea en el apoyo como en trabajos, tareas y cosas así pues la verdad no, no me ha quedado difícil porque pues yo tengo como conocimiento y trató como de ingeniármelas y de mostrarle, aunque a veces me saca de quicio y me toca pararme jajaja. (FbFc18)

De acuerdo con los testimonios anteriores se pude inferir que las familias terminan por convertirse en grandes estrategas de la enseñanza desde la casa, su apoyo en las tareas cuando requieren adaptaciones para facilitar al niño/a su elaboración, les incita a hacer uso de su imaginación e idear cualquier cantidad de actividades en miras de fortalecer el aprendizaje.

En esta medida no es erróneo afirmar que las tres familias de este estudio, de manera natural y a partir de algunas recomendaciones recibidas, terminan por realizar "ajustes razonables" en casa, entendidos estos desde el Decreto 1421 como "acciones, adaptaciones, estrategias, apoyos, recursos o modificacio- 
nes necesarias y adecuadas del sistema educativo y la gestión escolar" (Decreto 1421, 2017,Artículo 2.3.3.5.1.4), que buscan garantizar entre otros, el desarrollo y el aprendizaje del niño/a, con la aclaración de que ellas no hacen los ajustes al sistema educativo sino a su sistema de enseñanza en casa, a sus formas de acompañar y direccionar, pensando siempre en el bienestar de niño/a.

Respecto al acompañamiento en tareas, Bolívar (2006) señala que "es muy importante el apoyo en casa, éste se ve reforzado cuando hay una implicación en las tareas educativas desarrolladas por la escuela. Como efecto final, dicha implicación contribuye, a la larga, a mejorar el propio centro educativo" (p. 133).

Así mismo, es evidente en las tres familias el deseo y la acción por explorar otros ámbitos formativos y lúdicos más allá de los muros escolares y el anhelo de tener otras experiencias externas a la institución que también puedan ser formadoras para el niño/a, los que las hace veedoras y cumplidoras de lo expuesto en la ley estatutaria 1618 con relación a "una educación de calidad, definida como aquella que "forma mejores seres humanos, ciudadanos con valores éticos, respetuosos de lo público, que ejercen los derechos humanos y conviven en paz" (Ley estatutaria 1618, 2013, Articulo 11). Las visitas a otros espacios se vuelven parte de la rutina cotidiana y complemento de su participación en la educación de niño/a. Muestra de ello son los siguientes testimonios.

[...] está en el programa de discapacitados de aquí de la alcaldía de Medellín, ella estuvo en el centro cultural, en esos programas que dan allá para los niños de artística, pintura, de baile [...] (FaFc77)

[...] yo he ido a la biblioteca departamental a clase de señas, en el colegio, que hay actividades en tal lado, que en ASANSO, o sea en muchos lugares [...] (FbFc39)

[...] estuvimos muchos años en estímulos, digamos lo que yo te digo de los renglones, eso lo aprendí allá [...] (FcFc50)

El aprendizaje se da de manera integral y en diferentes espacios, no necesariamente en el ámbito institucional. Las familias reconocen que la posibilidad de que los niños/as sean participes, a partir del reconocimiento de su heterogeneidad, en otros lugares, abre las puertas para que complementen lo aprendido en la institución educativa y adquieran nuevos aprendizajes a partir de las relaciones sociales, interacción con otros, nuevas experiencias, integración de diferentes áreas, lo que indica que la inclusión hace parte de un trabajo conjunto y desde diferentes ambientes. En palabras de Valenciano (2009):

La inclusión $[\ldots]$ requiere un conjunto de acciones escolares, sociales y de la comunidad que eliminen las barreras que impiden la participación de los estudiantes en el aprendizaje, aceptando y valorando las diferencias individuales (p. 23).

Ahora bien, al momento de elegir colegio, para ninguna de las tres familias fue fácil, tener un niño/a con discapacidad implica que su educación debe darse en un lugar especial, una institución que les brinde garantías de atención y personal que sepa cómo enseñarles, o por lo menos así lo ven ellas. Las primeras experiencias no fueron del todo gratas, sitios donde los docentes no sabían que hacer ni como enseñar, fueron los que les tocaron a las familias $\mathrm{A}$ y $\mathrm{C}$, acciones de rechazo y segregación fueron suficientes para que retiraran al niño y la niña de esas instituciones y continuar la búsqueda de un lugar ideal para ellos. 
Tener que dejar su lugar de nacimiento y emprender una gran peregrinación también hace parte de la búsqueda del colegio ideal, aquel que tuviera las herramientas necesarias para la educación de un niño con discapacidad, historia vivida por la familia B quien abandonó las comodidades de su tierra natal para poderle brindar a su hijo un mejor futuro. Pareciera ser que el valor agregado que trae consigo la discapacidad es el reto de que las madres se colmen de valor y, siguiendo sus instintos, naden contra la corriente para llegar a esa meta propuesta por ellas mismas, la educación de los niños/as. Los siguientes testimonios deja ver parte de ello.

[...] fue duro, porque es un colegio pues normal, así, ahí son niños pues que no tienen ningún problema, me le hacían bullying a la niña, la profesora me la encerró una vez por allá por un salón, la encerró no, la llevo a otro salón y la dejó allá [...] (FaFc61)

[...] estuvo en jardines de bienestar con niños oyentes siendo que él no hablaba y el copiaba, que hacía el uno, que hacía el otro y esto y lo otro [...] (FbFc19)

[...] lo entré a otra institución, ese fue el peor año, nos fue super mal en esa institución [¿por qué?] Porque con esa profesora tuve mucho problema, como que no estaba acostumbrada a un niño con discapacidad, entonces me lo dejaba encerrado en el salón $[\ldots]$ ( $\mathrm{FcF}$ c55)

En ocasiones la elección del colegio no se da precisamente por deseo, esa decisión se toma por obligación, consejos de otros, búsquedas exhaustivas por las redes sociales, conversaciones informales con otros profesionales, deambular de un lado para otro, acudir al instinto materno, son algunas de las acciones que realizaron estas tres mujeres hasta llegar a la institución en la que hoy se encuentran matriculados los niños/as.
El conocimiento que tienen las madres de sus hijos es como una brújula que logra indicar hacía que dirección deben caminar y aunque legalmente existan unos parámetros a seguir, como lo es el caso del Decreto 1421 del 2017 que indica que todo estudiante con discapacidad debe recibir educación en la institución que se encuentre cerca a su casa, ellas en su interior sienten cuál es la institución indicada para el niño/a, ese fue el caso de la familia $\mathrm{C}$ quien después de acudir a Secretaria de Educación de Medellín determinó que lo allí establecido no era precisamente lo que requería su hijo.

Las tres familias convergen en plantear que la institución idónea es aquella que se acoge a las necesidades de ellos, sean atendidos de manera justa, que se les valore y respete como personas, un lugar que pueda ser el ideal para que los niños/as con discapacidad puedan recibir una educación con calidad, como lo dicen dos de las familias ( A y B), que cuente con docentes capacitados para la atención a personas con discapacidad. A continuación, se exponen relatos de las familias que atienden a esta tendencia. Ante la pregunta ¿La elección de esta institución fue por gusto o por obligación?

[...] él [odontólogo de la niña] me habló de ese colegio [...] que no era pues de totalmente de discapacitados pero que, sí recibe al niño y que tenía más prioridad pues con esos niños [con discapacidad], había pues inclusión [...] (FaFc62)

Por obligación, porque fue el único en el área metropolitana que me quedaba más cerca, porque incluso ya averigüé por acá cerca de la casa [...] Si hay varios colegios pero que decía, no aquí no tenemos profesor de lengua de señas, no tenemos ese conocimiento, no lo podemos aceptar [...] fui a la Secretaría de Educación [de Medellín] y me decían: no, es que cerca a la casa lo pude matri- 
cular $[. .$.$] pero a mí de qué me sirve que$ lo reciban en un colegio donde no le van a enseñar nada, le dije vengo de un proceso así, le dije porque es que yo tengo conocimiento en esto, le dije: "yo voy a meter a un niño a un colegio regular a qué, solamente por ir a ocupar un puesto, no me sirve" [...] (FbFc36)

[...] nos íbamos a pasar de barrio muy difícil encontrar un colegio digamos, así como éste (FLHB) no es que no pude [¿Cómo, así como éste?] Digamos que hayan... así que niños como con discapacidad, yo decía mira lo que pasa es que tengo un niño con discapacidad... Colegios que me recomendaban, a ¿qué discapacidad? ah parálisis cerebral infantil espástica, ¿y va al baño? ah sí y hace... Si, ah, pero no, de una no [no lo recibían]. (FcFc76)

En estos casos en particular aun cuando la elección del colegio tuvo grandes trasegares y pareciera ser obligada por ese ideal que tienen estas mujeres de una institución especial, una en la que sea reconocida la diversidad del niño/a, acogido e integrado con los requerimientos que ello implica, en la que se eliminen las barreras presentes y se permita al estudiante incluirse, las madres ante su desesperación y atendiendo a lo encontrado en su búsqueda ingresan al niño/a, a una institución con características particulares propias de una institución especial y no de una institución inclusiva, ello muestra la falta de claridad existente en estas mujeres respecto a lo que es la inclusión, ante esto Arnaiz (2003) expone que una institución educativa es inclusiva en la medida que atiende a las necesidades de los estudiantes mediante el desarrollo e implementación de "propuestas didácticas que estimulen y fomenten la participación de todos los alumnos" (Arnaiz, 2003, p. 35).

A pesar de que los niños y las niñas están matriculados y estudiando en una escue- la de educación inclusiva las tres familias manifiestan que no están de acuerdo con la inclusión. La familia $\mathrm{C}$ reitera que no ingresaría a su hijo a una institución inclusiva, ya lo intentó y fue una experiencia que no desea repetir, su hijo en un lugar así no podría estar. La familia A expresa estar muy feliz de tener a su nieta en esta institución (FLHB) porque es diferente en tanto la prioridad son aquellos estudiantes que están con discapacidad aun cuando estudian allí niños/ as que no tiene esta condición.

En definitiva es como si ambas madres se refirieran a una especie de inclusión a la inversa ${ }^{3}$ donde son los estudiantes sin discapacidad los que ingresan a una institución que siempre ha atendido estudiantes con discapacidad brindándoles educación acorde con sus habilidades y con las adaptaciones necesarias para alcanzar los logros académicos propuestos, diferente a todas las otras instituciones inclusivas en las que prima la presencia de estudiantes sin discapacidad y cuya atención se centra precisamente en ellos, instituciones inclusivas en las que sus niños/as ya fueron rechazados e incluso maltratados, en esta medida, estas mujeres parecen pensar que la institución donde estudian los niños/as no es posible que sea inclusiva debido a que el trato, atención y educación son muy diferentes a aquellas en las que ya han estado.

Yo entiendo como inclusión, no sé si estaré equivocada que es donde estudian niños de todas, que tengan discapacidad y que no tengan discapacidad, o sea que puedan integrarse juntos, estudiar juntos como lo está haciendo creo yo, el colegio, Laura con los otros niños [...] $(\mathrm{FaFc} 89)$

[...] yo no estoy de acuerdo con eso que están sacando de que los niños con discapacidad y niños regulares, yo no estoy de acuerdo con eso, o sea para mí 
eso no debería existir, no sé ni siquiera por qué la implementan o digamos en el caso digamos de mi hijo que estuviera en un colegio... él ya estuvo, y no sé, pero a mí me fue muy mal con él allá, o sea yo no estoy de acuerdo con la inclusión. $(\mathrm{FcFc} 58)$

Por su parte la familia B expresa que la inclusión no se trata de recibir niños con y sin discapacidad en un solo lugar, ésta se refiere a que todos los estudiantes hagan todo tipo de actividades, es decir que no se seleccionen acciones específicas según su condición y expone el caso del baile como ejemplo ante su disgusto (sordos/teatro, oyentes/ baile), enfatizando que las actividades de la institución que se dan a partir de los diferentes proyectos se encuentran agrupadas por poblaciones, los estudiantes con discapacidad auditiva solo tiene la posibilidad de estar en teatro y los oyentes en baile. Apreciación que llama la atención debido a que en este colegio (FLHB) desde lo plantado en PEI y constatado a partir de la asistencia de la investigadora a presentaciones y ensayos de danza dados en la institución, el proyecto de danzas está abierto a todos los estudiantes con y sin discapacidad. A continuación, el testimonio de la familia.

[...] la palabra inclusiva es en todas las actividades en todas y hay muchos profesores que creen que inclusivo es solamente que, porque el colegio recibe en niños oyentes y niños sordos, no la inclusión no viene de ahí ¿qué es la inclusión? La inclusión es o sea tanto los unos como los otros puedan comunicarse, puedan interactuar, puedan hacer sus actividades [...] los oyentes bailan, los sordos hacen teatro, no están incluyéndolos. (FbFc67)

A partir de los testimonios anteriores es posible evidenciar la falta de conocimiento por parte de las familias respecto a cómo funciona la institución educativa en la que se encuentran matriculados los niños/as, lo que da como resultado en ellas la asunción de ideas erradas o confusas sobre lo que es la educación inclusiva y cuáles son los principios rectores que la orientan y fundamenta en esta institución.

Respecto a ello, a partir de la lectura del PEI de la IE FLHB fue posible establecer que esta institución efectivamente es de carácter inclusivo en la medida que sus prácticas pedagógicas están encaminadas a la atención por la diferencia como característica de la diversidad y condición inherente a todas las personas, en coherencia con los principios institucionales que van en miras del reconocimiento de que todos podemos aprender, todos aprendemos de manera diferente, el respeto por las diferencias individuales, entre otros. Además, su modelo pedagógico social desarrollista se enfatiza en tres compendios rectores, atención con calidad, pertinencia y equidad para todos los estudiantes, con y sin discapacidad y se acoge a leyes y decretos propios de la educación inclusiva como los son la ley estatutaria 1618 del 2013 y el decreto 1421 del 2017.

\section{Conclusiones}

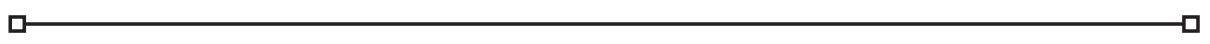

El concepto de participación para estas familias a partir de sus experiencias vividas, alude al acompañamiento y apoyo en todos los procesos que tengan que ver con el desarrollo integral del niño/a con discapaci- dad, tales como: citas médicas/especialistas, creación de material y estrategias para el apoyo en casa, asistencia a reuniones, acompañamiento en clases extracurriculares, así como, encontrar una institución educativa 
que posibilite un mejor aprendizaje y por ende un mejor futuro para el niño/a. Ellas ven la participación en dicha educación como una acción que requiere de esfuerzo y dedicación, y se convierte en un reto personal que se asume pensando en el bienestar del niño/a. Si bien para cada familia sus experiencias son diferentes, es posible afirmar a partir de este estudio, que, para las tres familias participantes, la discapacidad es una condición que puede generar indiferencia cuando ésta no ha atravesado los muros de un hogar, pero cuando los traspasa, las familias se vuelven más sensibles a ella, lo que les posibilito en este caso, generar estrategias de participación en la educación inclusiva de sus hijos/nieta.

Asimismo, este estudio permitió identificar desde las miradas y experiencias de las familias, el reconocimiento que tienen de las necesidades de sus hijos/nieta, así como su disposición para participar en el fortalecimiento de sus habilidades "trató como de ingeniármelas y de mostrarle [...] he ido a la biblioteca departamental a clase de señas" (Familia B). En contraste con ello la investigación realizada por González, Martín y Poy (2019) con docentes de Castilla y León - España respecto a su apreciación sobre la inclusión, expone en sus resultados que los docentes sienten que las familias son barreras para la educación inclusiva en tanto no reconocen las dificultades académicas que tienen sus hijos.

A modo de recomendación, sería pertinente en otros estudios acercarse a las miradas de los docentes y de los mismos niños y niñas con el fin de reconocer la experiencia subjetiva de estas poblaciones en tanto ellas también hacen parte del tejido social y comunitario que implica la educación inclusiva. Podría realizarse, además, un estudio similar cuya invitación sea explícita para los hombres (padres, abuelos, tíos, hermanos...) con el fin de escuchar lo que ellos tienen para decir respecto a su participación en la educación inclusiva del niño/a con discapacidad.

\section{Notas}

1. Este artículo se deriva de la investigación La participación familiar en la educación inclusiva de estudiantes con discapacidad realizada en el marco de la Maestría en Estudios en Infancias de la Universidad de Antioquia 2018-2020.

2. Anteriormente llamada en la IE FLHB escuela de padres y cuyo nombre se cambió por escuela de familias teniendo en cuenta que no todos los acudientes de los estudiantes son los padres.

3. Término usado en el PEI de la IE FLHB que hace referencia a un proceso de inclusión diferente al de las demás instituciones educativas públicas del departamento de Antioquia, en la medida que son los estudiantes con discapacidad sensorial quienes acogen a aquellos sin discapacidad.

\section{REFERENCIAS}

Abad, A. (2016). Familia y discapacidad: consideraciones apreciativas desde la inclusión. Revista Latinoamericana de Estudios de Familia (8), 58-77. http://vip.ucaldas.edu.co/revlatinofamilia/ downloads/RLEF\%208-completa.pdf\#page=58. 
Arnaiz, P. (2003). Educación Inclusiva: Una escuela para todos. Málaga, España: Aljibe.

Beltrán, Y., Martínez, Y., y Torrado, O. (2015). Creación de una comunidad de aprendizaje: una experiencia de educación inclusiva en Colombia. Revista Encuentros, 13(2), 57-72. http://ojs.uac. edu.co/index.php/encuentros/article/view/498/394

Bolívar, A. (2006). Familia y escuela: dos mundos llamados a trabajar en común. Revista de educación, 339(1), 119-146. https://www.forofamilia.org/documentos/FAMILIA\%20-\%20Familia\%20 y\%20escuela.\%20Dos\%20mundos\%201lamados\%20a\%20trabajar\%20en\%20comun..pdf

Castro, A., y García, R. (2016). Vínculos entre familia y escuela: visión de los maestros en formación. Magis. Revista Internacional de Investigación en Educación, 9(18), 193-208. https://www. redalyc.org/pdf/2810/281049122011.pdf

Congreso de Colombia. (2013, 27 de febrero). Ley estatutaria. [1618 del 2013]. DO: 48.717

Duarte, J. (2006). La comunicación: una experiencia pedagógica de desarrollo humano. Revista Educación y Pedagogía, 46(XVIII), 191 - 202. http://bibliotecadigital.udea.edu.co/handle/10495/3053

Galeano, M. (2004). Diseño de proyectos en la investigación cualitativa. Medellín, Colombia: Fondo editorial Universidad EAFIT.

García, F. (1994). La interacción escuela - familia. En G. Musitu y p. Allatt (Eds.), Psicosociología de la familia (pp., 273 - 292). Valencia: Albatros Educación.

Gervilla, Á. (2015). Familia y educación familiar. Conceptos clave, situación actual y valores. Madrid: Narcea.

González, F., Martín, E., y Poy, R. (2019). Educación inclusiva: barreras y facilitadores para su desarrollo. Análisis de la percepción del profesorado. Profesorado, Revista de Currículum y Formación del Profesorado, 23(1), 243-263. https://doi.org/10.30827/profesorado.v23i1.9153

Larrosa, J. (2006). Sobre la experiencia. Aloma. Revista de Psicologia i Ciències de l'Educació, núm. (19), 87-112.

López, N. (2017). Funcionalidad familiar y participación escolar de las familias de niños con discapacidad. IE Revista de investigación educativa de la REDIECH, 8(14), 111-128. https://www. redalyc.org/articulo.oa? $\mathrm{id}=521653267018$

Madrigal, A. (2007). Familias ante la parálisis cerebral. Psychosocial Intervention, 16(1), 55-68. http://scielo.isciii.es/pdf/inter/v16n1/v16n1a05.pdf

Marín, F., Arnaiz, P., y Giménez, A (2015). La participación de la familia en la escuela inclusiva: una experiencia de investigación en educación infantil. En Maquilán, J. y Orcajada, J. (Ed.), Investigación y acción educativa en infantil y primaria (1 ${ }^{\mathrm{a}}$. ed.) (pp. 59-72). https://dialnet.unirioja.es/ servlet/articulo? codigo $=5979108$

Melo, P. (2017). Percepciones sobre la participación familiar del Proyecto de Integración Escolar en un colegio municipal de Chile. Revista de Educación Inclusiva, 10(2), 147-164. https://revistaeducacioninclusiva.es/index.php/REI/article/view/323 
Núñez, B. (2003). La familia con un hijo con discapacidad: sus conflictos vinculares. Arch Argent Pediatr, 101(2), 133-142. http://www.ardilladigital.com/DOCUMENTOS/CALIDAD\%20 DE $\% 20$ VIDA/FAMILIA/La $\% 20$ familia\%20con $\% 20$ un $\% 20$ hijo $\% 20$ con $\% 20$ discapacidad $\% 20$ -\%20Blanca\%20Nunyez\%20-\%20articulo.pdf

Núñez, B., Páez, S., y Pérez, M. (2017). Futuro, familia y discapacidad. Ciudad Autónoma de Buenos Aires: Lugar Editorial.

Ordoñez, E. (2016). La investigación en familias de personas con discapacidad. Paideia Surcolombiana, 21(21), 12-26. https://journalusco.edu.co/index.php/paideia/article/view/1443

Ortega, P., Torres, L., Reyes, A., y Garrido, A. (2010). Paternidad: niños con discapacidad. Revista Intercontinental de psicología y educación, 12(1), 135-155. https://www.redalyc.org/ pdf/802/80212393008.pdf

Palacio, M. C. (2009). Los cambios y transformaciones en la Familia. Una paradoja entre lo sólido y lo líquido. Revista Latinoamericana Estudios de familia, 1(2), 46-60. http://revlatinofamilia. ucaldas.edu.co/downloads/Rlef1_3.pdf

Palacio, M. C. (2010). Los tiempos familiares en la sociedad contemporánea: La trayectoria de una configuración. Revista Latinoamericana Estudios de familia, (2), 9-30. http://vip.ucaldas.edu.co/ revlatinofamilia/downloads/Rlef2_1.pdf

Parra, J., Gomariz, M., Hernández, M. y García, M. (2017). La participación de las familias en educación infantil. Relieve, 23(1), 1-26. https://ojs.uv.es/index.php/RELIEVE/article/view/9258/9657

Parrellada, C. (2008). ¿Se invaden, se necesitan...? Cuadernos de Pedagogía,

(378), 47-51.

Peralta, F., y Arellano, A. (2013). Familia y discapacidad. Una perspectiva teórico-aplicada del Enfoque Centrado en la Familia para promover la autodeterminación. Electronic Journal of Research in Educational Psychology, 8(3), 1339-1362. http://riberdis.cedd.net/handle/11181/3638

República de Colombia. (2017, 29 de agosto). Decreto 1421. Presidente de la república de Colombia. https://www.mineducacion.gov.co/1759/w3-article 381928.html?_noredirect=1

Strauss, A., y Corbin, J. (2002). Bases de la investigación cualitativa. Técnicas y procedimientos para desarrollar la teoría fundamentada. Medellín: Editorial Universidad de Antioquia.

Valenciano, G. (2009). Construyendo un proyecto de educación inclusiva: una experiencia compartida. En: Sarto, M., y Venegas, M. (1 ${ }^{\mathrm{a}}$ ed.), Aspectos clave de la Educación Inclusiva (pp. 13-24). Salamanca, España: Instituto Universitario de Integración en la Comunidad. https://sid.usal.es/ idocs/F8/FDO22224/educacion-inclusiva.pdf

Valanzuela, C., y Sales, A. (2016). Los efectos de la participación familiar dentro del aula ordinaria (Effects of family involvement within the ordinary class). Revista nacional e internacional de educación inclusiva, 9(2), 71-86. https://revistaeducacioninclusiva.es/index.php/REI/article/ view/288/269

Vallejo, (2001). Duelo de los padres ante el nacimiento de un niño con discapacidad. Iatreia, 14(2). https://revistas.udea.edu.co/index.php/iatreia/article/view/3805 